\title{
Maintenance of polar stratospheric clouds in a moist stratosphere
}

\author{
D. B. Kirk-Davidoff ${ }^{1}$ and J.-F. Lamarque ${ }^{2}$ \\ ${ }^{1}$ University of Maryland, Department of Atmospheric and Oceanic Science, 3423 Computer and Space Sciences, College \\ Park, MD 20742, USA \\ ${ }^{2}$ National Center for Atmospheric Research, Atmospheric Chemistry Div., P.O. Box 3000, Boulder, CO 80307-3000, USA
}

Received: 4 July 2007 - Published in Clim. Past Discuss.: 10 July 2007

Revised: 13 February 2008 - Accepted: 4 March 2008 - Published: 31 March 2008

\begin{abstract}
Previous work has shown that polar stratospheric clouds (PSCs) could have acted to substantially warm high latitude regions during past warm climates such as the Eocene $(55 \mathrm{Ma})$. Using a simple model of stratospheric water vapor transport and polar stratospheric cloud (PSC) formation, we investigate the dependence of PSC optical depth on tropopause temperature, cloud microphysical parameters, stratospheric overturning, and tropospheric methane. We show that PSC radiative effects can help slow removal of water from the stratosphere via self-heating. However, we also show that the ability of PSCs to have a substantial impact on climate depends strongly on the PSC particle number density and the strength of the overturning circulation. Thus even a large source of stratospheric water vapor (e.g. from methane oxidation) will not result in substantial PSC radiative effects unless PSC ice crystal number density is high compared to most current observations, and stratospheric overturning (which modulates polar stratospheric temperatures) is low. These results are supported by analysis of a series of runs of the NCAR WACCM model with methane concentrations varying up to one thousand times present levels.
\end{abstract}

\section{Introduction}

The fundamental challenge to climate dynamics posed by the paleoclimate record of the Eocene, when polar winter temperatures were well above freezing, but tropical temperatures were not much warmer than at present, remains unresolved (Huber and Sloan, 2001). Sloan and Pollard (1998) and KirkDavidoff et al. (2002), hereinafter referred to as KSA) investigated the possible role of polar stratospheric clouds (PSCs) in maintaining the extreme polar warmth of the Eocene

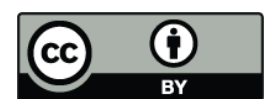

Correspondence to: D. B. Kirk-Davidoff (dankd@atmos.umd.edu) climate. Sloan and Pollard (1998) showed that an optically thick (optical depth $\tau=1$ ) cloud inserted into a GCM stratosphere substantially warmed polar surface temperatures. KSA examined the plausibility of a dynamical feedback mechanism whereby reduced pole-to-equator temperature difference could yield reduced stratospheric overturning, increased tropical tropopause temperature, a moister stratosphere, increased PSC optical depth, polar warming and thus further reduced pole-to-equator temperature difference. They showed that this feedback cycle led to clouds formed under plausible physical constraints (reasonable cloud particle number density, cloud water content, and explicitly calculated optical depth) with sufficient optical depth (though generally less than unity) to warm the polar surface.

Recently, Korty and Emanuel (2007) have investigated the response of the stratospheric overturning circulation and temperature distribution to a dramatic change in the surface temperature gradient in a GCM with enhanced stratospheric resolution. They find no reduction in overturning strength, but do note an increase in tropical tropopause temperature, probably due to increased tropical surface temperatures (by $3 \mathrm{~K}$ ) imposed in their model. Model results for the dependence of stratospheric overturning on surface temperature distribution vary widely among GCMs since, as discussed in KSA the net effect of overturning is the result of two conflicting responses to surface temperature changes: a positive dependence of baroclinic eddy amplitude on meridional temperature gradient, and a negative dependence of the ability of planetary waves to propagate upwards through the tropopause on the meridional temperature gradient.

KSA left many details of their proposed feedback cycle untested. They did not take into account either the reduction of water vapor transport to the polar cap that would accompany reduced overturning circulation, or the loss of stratospheric water vapor due to sedimentation of PSC ice particles. Here we explore these aspects of the stratospheric water vapor budget using both the NCAR Whole-Atmosphere

Published by Copernicus Publications on behalf of the European Geosciences Union. 
Community Climate Model (WACCM) and the moderatecomplexity model described in KSA, modified to account for transport of tracers by the stratospheric mean circulation, and to include loss of water by sedimentation of cloud particles. We analyze the stratospheric water vapor budget and cloud formation in simulations performed using WACCM to investigate the radiative and chemical role of increased methane in the Permian atmosphere (Lamarque et al., 2006). In those simulations, stratospheric clouds are governed by the same parameterizations used in the troposphere, with cloud ice size depending purely on temperature. Using our moderate-complexity model, we test the sensitivity of PSC optical depth to assumptions about the ice crystal physics, cloud-radiation interactions, tropospheric temperature distribution and stratospheric overturning circulation strength. We use the our model for these experiments, because its lower dimensionality allows for shorter integration times, facilitating a broad exploration of parameter space, and because it allows us to focus finite computational resources on the microphysical aspects of the problem that are most uncertain, rather than on the detailed calculation of atmospheric motions whose main effect is to transport material from the tropical tropopause through the bulk of the stratosphere.

The microphysics of PSCs are understood only approximately, so that extrapolation to conditions of substantially higher stratospheric water vapor is difficult. In the modern atmosphere, PSCs form every winter in both the Arctic and Antarctic stratosphere. In the Arctic they consist primarily of Nitric Acid Trihydrate (NAT) crystals (type I PSCs), and are mostly found in cold regions formed by gravity waves in the lee of mountain ranges. These clouds are able to substantially reduce stratospheric nitrogen content over the course of the winter, but do not remove much water (Drdla et al., 2002). Colder temperatures in the Antarctic winter allow formation of water ice clouds (type II PSCs) by freezing of sulfuric acid droplets. By the end of the winter, sedimentation of the ice crystals forming these clouds results in substantial dehydration of the polar vortex. These PSCs typically have number densities of $0.01-1 \mathrm{~cm}^{-3}$ and crystal sizes of a few microns (Peter, 1997).

The factors controlling the number density of type II PSCs are also poorly understood. They include both physical factors such as the availability of background aerosol particles, whose density varies over a wide range depending on latitude, altitude, season and volcanic activity, and dynamical factors such as the speed of the cooling that leads to condensation and cloud formation (Peter, 1997). PSC number densities tend to be larger when clouds are formed rapidly (as in mountain wave clouds), and smaller when clouds are formed slowly (Toon et al., 1989; Hu et al., 2002). This is because, in clouds formed by slow cooling, supersaturation ratios are relatively low, and freezing occurs preferentially among aerosols that largely consist of hydrated nitric acid (Tabazadeh et al., 1997). In rapid cooling, with high supersaturations, nearly all the stratospheric aerosol are "activated", allowing homogeneous freezing, and optical depths approaching unity, while preventing much sedimentation (due to small particle size).

The subject of how PSC number density might change in radically different climates over geological time has not been much studied. Reasons for increasing number density would include larger volcanic emissions of $\mathrm{SO}_{2}$ leading to increasing aerosol number density (at least of larger particles - observations of stratospheric condensation nuclei number density show no strong differences between volcanic and nonvolcanic years (Deshler et al., 2003)) and a change in role of nitric acid trihydrate (NAT). In the current climate dehydration processes are modulated by the uncertain role of NAT as a competitor with smaller water ice particles for water vapor (Drdla et al., 2002; Carslaw et al., 1997). In a moister stratosphere, NAT would play a less important role, since ice nucleation would occur at warmer temperatures, so supercooling of sulfate aerosol could be sufficient to allow nucleation at temperatures above the NAT nucleation threshold. PSC number density would then be more dependent on sulfate aerosol number density. The number density of stratospheric aerosol is controlled by nucleation and coagulation of liquid sulphate solution in the upper tropical troposphere, whence aerosol droplets are transported upwards into the stratosphere, and by conversion of OCS (carbonyl sulfide) to $\mathrm{SO}_{2}$ and $\mathrm{H}_{2} \mathrm{SO}_{4}$ in the upper stratosphere (Thomason and Peter, 2006). Stratospheric aerosol number density varies over an order of magnitude or more depending on location and time. "Background" levels, in the absence of direct injection of $\mathrm{SO}_{2}$ by volcanic eruptions, range from 1 to $10 \mathrm{~cm}^{-3}$. Daerden et al. (2007) discuss the role of uncertainties in the aerosol size distribution for models of PSC formation.

Our approach in the face of these uncertainties will be to model PSC radiative properties over a wide range of possible PSC number densities. In this way we can estimate how the various still unknown features of the past stratosphere might constrain the role of PSCs in warming the poles. PSC properties are typically either neglected or treated in a greatly simplified manner in climate models. When they are specifically predicted for studies of stratospheric chemistry, their radiative interactions are often assumed away, while climate prediction models typically use empirically designed cirrus parameterizations derived from tropospheric observations to predict stratospheric cloud properties as well. Since the distribution of potential cloud condensation nuclei is quite different in the stratosphere and troposphere (Brock et al., 1995), it is not clear that this approach is well justified.

In this paper we will address the following questions:

- For which particle number densities is substantial infrared radiative heating by PSCs possible?

- Does radiative heating of PSCs themselves substantially affect their abundance? 

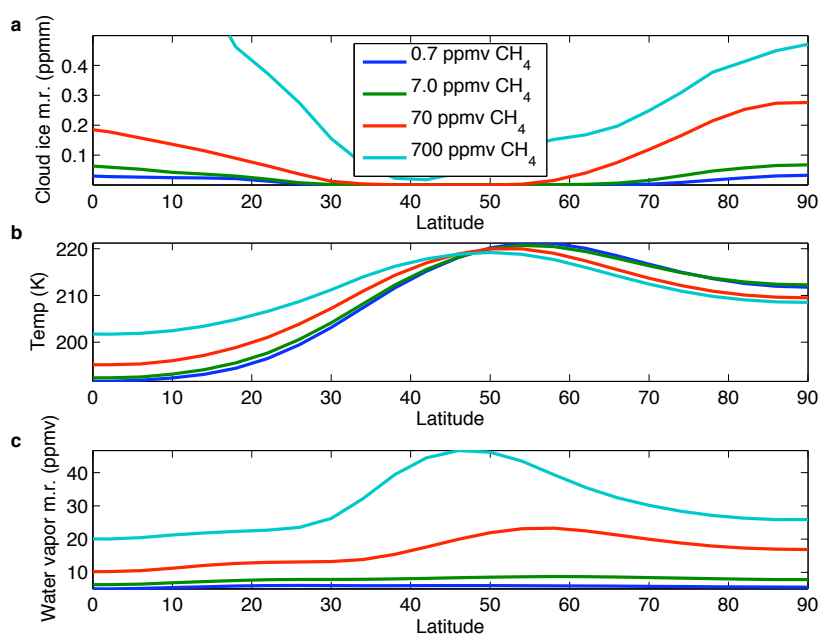

Fig. 1. Results from three WACCM runs with Permian boundary conditions and varying tropospheric methane concentrations. (a) $75 \mathrm{hPa}$ cloud water mass mixing ratio. (b) $75 \mathrm{hPa}$ Temperature (K). (c) $75 \mathrm{hPa}$ water vapor volume mixing ratio.

- In a low-temperature gradient world, are thick PSCs possible without a reduction in stratospheric overturning?

- In a low-overturning world, can sufficient water vapor be provided to the poles to match sedimentation and produce substantial PSCs?

- Can additional methane alone, without changes to overturning circulation cause substantial increases in PSC optical depth?

\section{Results from WACCM experiments}

In this section we review relevant results from a series of experiments performed using the NCAR WACCM, intended to simulate the impact of a large release of methane at the end of the Permian. The model and boundary conditions for these experiments are described in detail in Lamarque et al. (2006). Here we focus on the influence of changing tropospheric methane concentrations on stratospheric water vapor and cloud fraction. Tropospheric methane concentrations are made to vary over three orders of magnitude, from $0.7 \mathrm{ppmv}$ (close to pre-industrial levels) to $700 \mathrm{ppmv}$. Figure 1 shows cloud ice mixing ratio, temperature and water vapor mixing ratio, all at the model level corresponding to about $72 \mathrm{hPa}$. As expected, increasing tropospheric methane yields increasing water vapor. Methane oxidizes to water vapor as air ages, resulting in an increase in water vapor from the tropics to the mid-latitudes. Beyond the mid-latitudes, water vapor is lost due to cloud formation and precipitation formation. In WACCM, ice crystal size is a function of temperature only, with stratospheric temperatures yielding crystals sizes of about $30 \mu \mathrm{m}$ for temperature of $210 \mathrm{~K}$ (compared

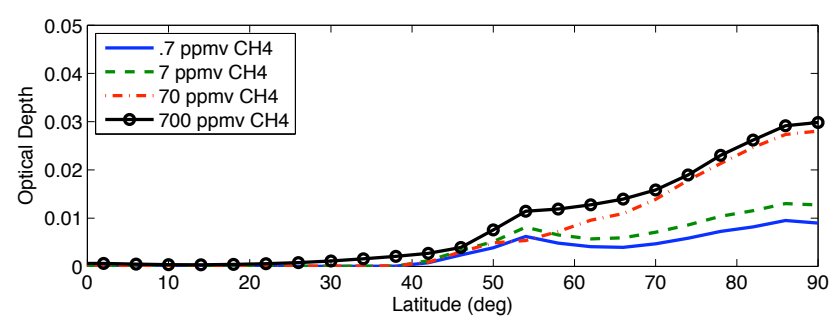

Fig. 2. Optical depth of stratospheric ice clouds for the four experiments with varying methane.
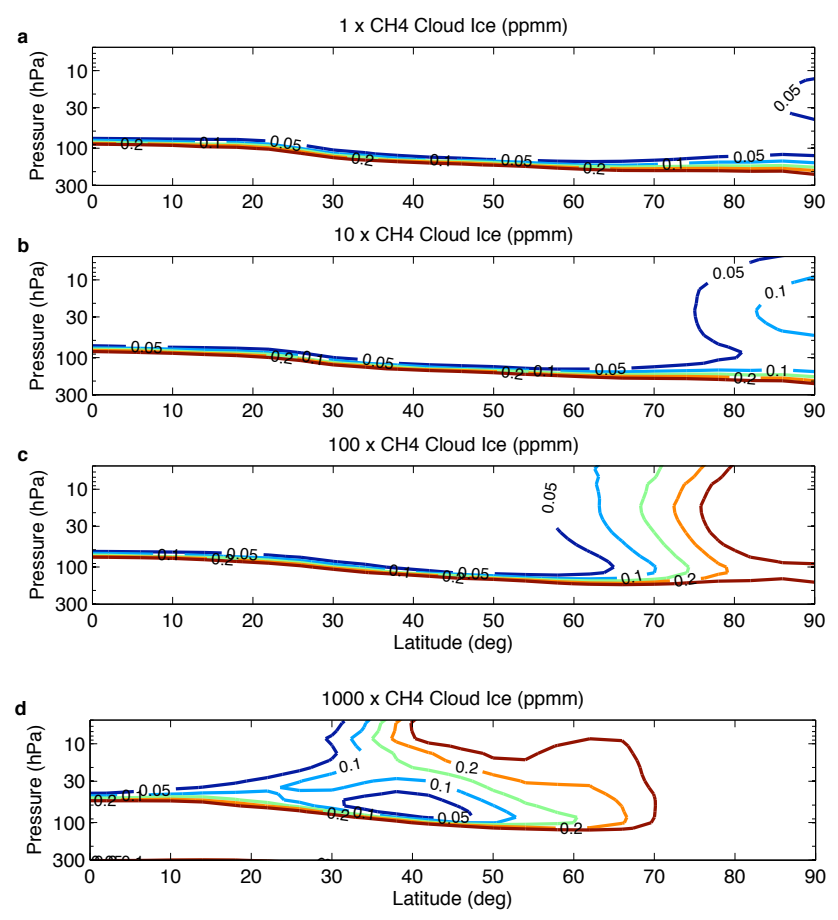

Fig. 3. Contours of stratospheric cloud ice mixing ratio for four WACCM runs with Permian boundary conditions, with tropospheric methane concentrations of 1, 10, 100 and 1000 times pre-industrial concentrations of $700 \mathrm{ppmv}$. Contour interval is 0.05 ppmm of cloud ice.

to typical observed PSC linear dimensions of 1-2 $\mu \mathrm{m}$ (Hu et al., 2002). In addition, beyond about 3 ppmm of cloud ice, conversion to snow takes place, which results in a very rapid loss of cloud ice. These factors combine to prevent annual mean PSC optical depth from reaching high levels, despite the large water vapor source due to methane oxidation, as shown in Fig. 2. Optical depth was calculated from cloud ice mixing ratio in the stratosphere (defined by the thermal tropopause) and the parameterized relationship between temperature and effective radius used by WACCM. Because of the low cloud optical depths, Fig. 3 shows very smooth concentrations of cloud ice, without any of the patchiness due to PSC self-heating evident that occurs in our model (see next section). 

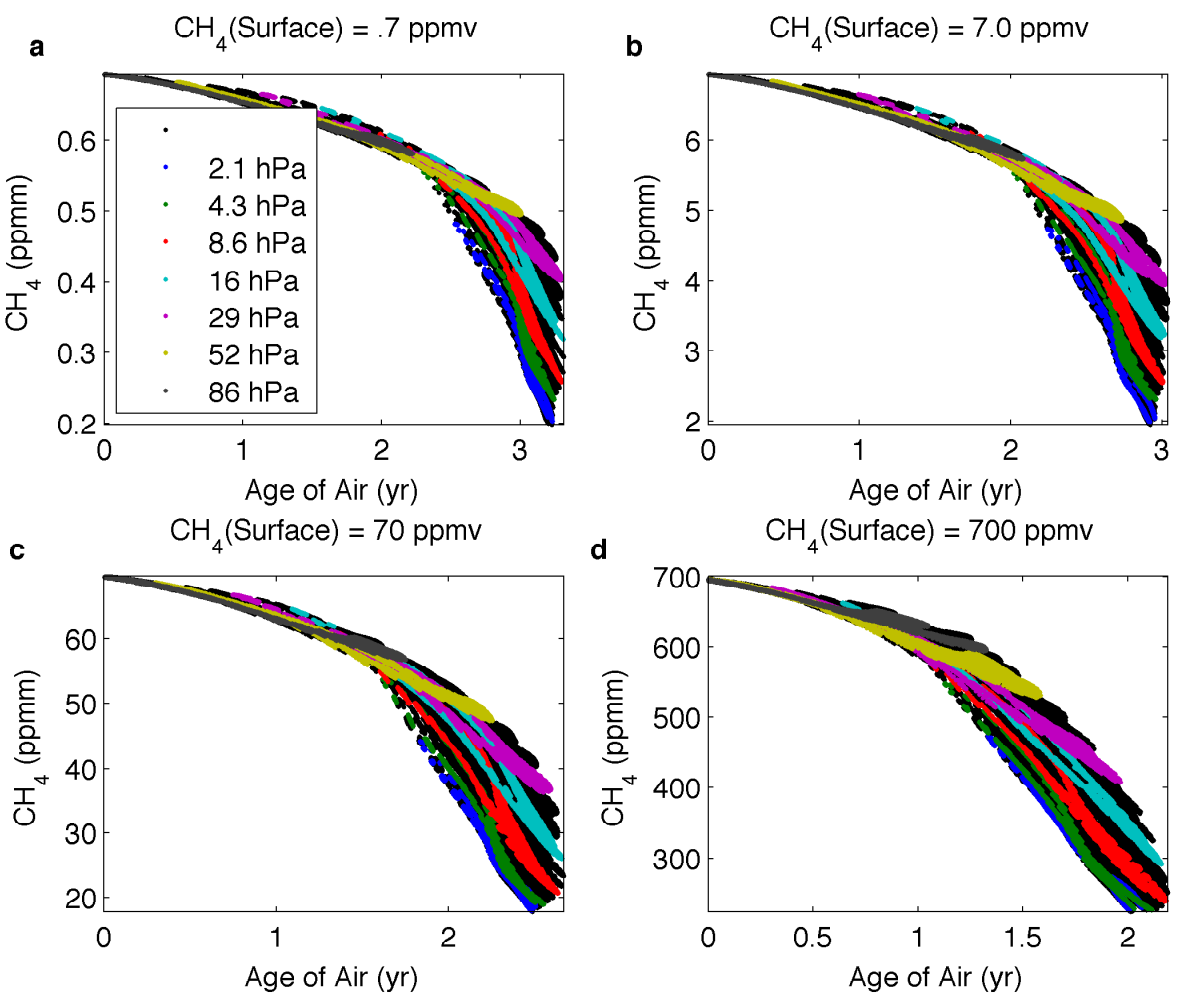

Fig. 4. Mass mixing ratio of Methane $\left(\mathrm{CH}_{4}\right)$ plotted against age of air. Different model levels (labeled with their average pressure level) are denoted by different colors, as labeled in the legend.

Figure 4 shows plots of methane concentration versus age of air (the number of years since a parcel in the stratosphere entered the stratosphere via the tropical tropopause). There is a nearly monotonic relationship between age of air and methane concentration, and also between age of air and latitude (not shown). This compact relationship enables our model, with its trivial transport scheme (in which air moves at a constant rate from the tropics to the poles) to approximately reproduce the patterns of methane, water vapor and cloud ice seen in WACCM, if ice parameters are adjusted so that PSCs have little infrared optical depth.

In the following sections we use our simple model to explore the role that PSCs might have played in past warm climates, under a wide range of assumptions governing the behavior of cloud ice and the stratospheric environment. Such a wide range of assumptions would be difficult to implement in the full model, but may lead to insight into which aspects of the full model might be reasonably varied to yield a better estimate of the uncertainty in the role played by PSCs in past climate.

\section{Simple model description}

The model used to predict the stratospheric water vapor budget and polar stratospheric cloud formation under varying assumptions of particle number density and stratospheric over- turning is described in detail in Kirk-Davidoff and Lindzen (2000) and in KSA. In the calculations described below, the model is run with prescribed, seasonally varying surface temperature, to focus on the behavior of the PSCs. This simple model is not intended to produce accurate estimates of PSC radiative forcing for any particular distribution, but rather to explore the relative importance of PSC radiative effects and feedback mechanisms under a wide range of assumptions about the such unknown features of the Eocene atmosphere as the PSC particle number density, trace gas concentrations and the strength of the Brewer-Dobson circulation.

The model is two dimensional in pressure and latitude, with a meridional resolution of three degrees latitude, and a vertical resolution of $15 \mathrm{hPa}$ in pressure, except for some runs we have done at $6 \mathrm{hPa}$ vertical resolution for comparison purposes. The top model layer is at $8 \mathrm{hPa}(2 \mathrm{hPa}$ for the high resolution runs). Tropospheric temperatures are set to lie along moist adiabats in the tropics, while an assumed fixed distribution of potential vorticity results is used to determine the temperature in the mid-latitude troposphere, given the surface temperature, and the surface static stability. Tropospheric relative humidity is fixed. Temperatures in the stratosphere are allowed to come into radiative equilibrium through a thermodynamic equation, and the tropopause height is chosen to minimize the temperature discontinuity at the tropopause. The radiative heating terms are calculated 
using the schemes of Chou et al. (2001) and Chou and Suarez (1999). Ozone concentrations are a fixed function of height and latitude, so the ozone feedbacks investigated in Lamarque et al. (2006) are not considered. Methane and $\mathrm{CO}_{2}$ are treated as well-mixed in the vertical and are held fixed at their tropospheric values for radiative purposes. The stratospheric overturning is represented by a term of the form:

$Q_{B D}=0.8 \mathrm{Kd}^{-1} \frac{\Delta T_{p e}}{45 \mathrm{~K}} \cos (\pi \sin (\phi))$

where $Q_{B D}$ is the heating due to the stratospheric overturning (Brewer-Dobson) circulation, $\Delta T_{p e}$ is the pole-toequator temperature difference in the present hemisphere, and $\phi$ is the latitude. $Q_{B D}$ is brought to zero from $50 \mathrm{hPa}$ to the model top with a linear pressure dependence. The two constants are chosen so that for the present climate conditions, the mean stratospheric cooling due to the overturning averages to $0.5 \mathrm{~K}$ over the tropical region. As discussed in KSA, the dependence of the stratospheric overturning circulation on the surface temperature gradient is based on the idea that tropospheric temperature gradients should control baroclinic wave growth rates, and that tropospheric waves propagating into the stratosphere and breaking there are the cause of upwelling in the tropical stratosphere and downwelling in the polar stratosphere (Holton et al., 1995; Kawamoto and Shiotani, 2000).

The surface static stability varies linearly with latitude so that it is continuous across the edge of the tropics at 30 degrees latitude in each hemisphere, and approaches a value at the poles that is adjusted so that the isentrope leaving the surface at the equator intersects the tropopause at the poles. This has the effect of reducing polar static stability as the pole-toequator temperature difference decreases, a tendency that is robustly observed in GCM simulations with varying surface temperature gradients (Schneider, 2004; Korty and Emanuel, 2007).

Cloud fraction and optical depth are fixed in the troposphere. In the stratosphere they are calculated as follows. Ice particle number density is taken to be an adjustable parameter, but is held fixed for the duration of each model run. Cloud ice mixing ratio set equal to excess of water vapor mixing ratio over saturation mixing ratio. Excesses can occur due to local cooling or to transport of water vapor. The effective radius of stratospheric cloud ice particles is derived from number density and cloud ice mixing ratio, assuming spherical particles, so that

$R=\left(\frac{3}{4 \pi N \rho_{i}} r_{i}\right)^{1 / 3}$

where $R$ is the effective radius, $N$ is the particle number density, $r_{i}$ is the cloud ice mixing ratio, and $\rho_{i}$ is the density of ice. The assumption of spherical particles is reasonable considering observations of quasi-spherical particles in subvisible cirrus (Peter, 1997). We have also tested sensitivity of our results to an alternative assumption that cloud particles form as needles, using the parameterization of (Heymsfield and Iaquinta, 2000). Assuming needles results in only small differences in cloud radiative properties, because the particles are in a size range of a few microns where fall speeds are not dramatically different for the alternative assumptions.

Water loss by cloud particle sedimentation is determined by assuming that particles fall at the Stokes velocity, with no reevaporation:

$v_{s}=\frac{2}{9} \frac{\rho_{i} g}{v \rho} R^{2}$

where $v_{s}$ is the Stokes velocity, $g$ is the acceleration of gravity, $v$ is the kinematic viscosity of air, and $\rho$ is the air density. Sensitivity studies were conducted to test the dependence of model results to re-evaporation. Allowing complete reevaporation of all particles lost from a given layer into subsaturated layers below increased vertically integrated stratospheric cloud optical depths by up to $100 \%$ compared to the no-reevaporation case. Changes were largest in the case of small number density, when water vapor losses to sedimentation were largest. Because cloud optical depths were smallest in those cases, this sensitivity is unlikely to influence any of our qualitative conclusions.

Sensitivity tests at higher resolution $(6 \mathrm{hPa})$ show some stratospheric temperature bias with resolution: temperature increase at $75 \mathrm{hPa}$ by about $5 \mathrm{~K}$ at higher resolution. This resolution-dependent temperature bias results in a tendency towards lower PSC optical depths at higher resolution. These biases do not affect any of the qualitative results shown below.

Cloud water infrared optical depth is calculated in the Chou et al. (2001) code by assuming spherical particles, and using a ten band look-up table for IR extinction coefficients:

$\tau(l)=P_{i} *\left(a_{1}(l)+\frac{a_{2}(l)}{R^{a_{3}(l)}}\right)$

where $\tau(l)$ is the optical depth for frequency band $l, P_{i}$ is the liquid water path, equal to $r_{i} \rho$, and $a_{1}(l), a_{2}(l)$ and $a_{3}(l)$ are empirical parameters.

Figure 5 shows the relationships between cloud water mixing ratio and cloud particle size, cloud water sedimentation loss rate for a $15 \mathrm{hPa}$ grid box, and cloud water optical depth (for the $1100-1215 \mathrm{~cm}^{-1}$ band) that result from these relationships.

Transport of water and methane in the stratosphere are controlled by a simple semi-lagrangian differencing scheme, such that transport occurs only in the meridional dimension, and only in the poleward direction. At the equator, water vapor throughout the stratosphere is set to its value at the tropopause, while methane is set to its tropospheric value. As with the warming or cooling due to the overturning circulation, the magnitude scales linearly with the pole-to-equator temperature difference, so that for modern conditions water and methane are transported poleward with a velocity of 3 degrees latitude per month, yielding an "age of air" of 

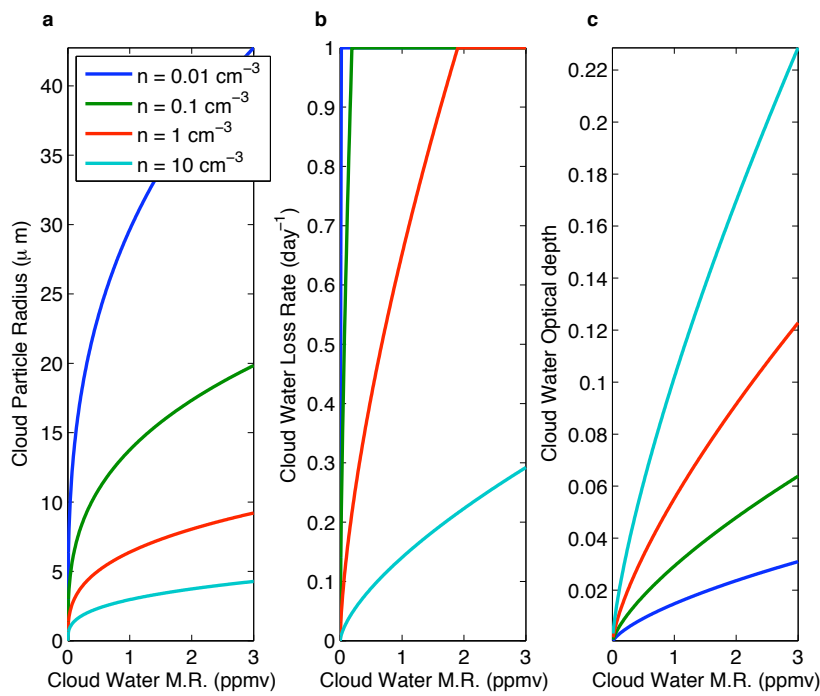

Fig. 5. Parameterized relationships between cloud water mixing ratio and (a) particle radius, (b) cloud water loss rate due to sedimentation and (c) cloud water optical depth for a $10 \mathrm{~km}$ deep region with uniform cloud water mixing ratio.

about 3 years at the poles. This is fast compared to observed ages of air of 4 to 5 years, but agrees with typical model results (Scheele et al., 2005), including results for the WACCM cases we discuss here. For the Eocene case, the overturning circulation speed is cut by a factor of three, yielding an "age of air" of 9 years at the pole. We also perform sensitivity experiments showing results for "Modern" overturning with "Eocene" surface temperatures, and vice versa. Methane is converted to water vapor at a rate of $2 \%$ per month, which results in a conversion of about $2 / 3$ of methane by the time air reaches the poles for modern conditions. Unless otherwise stated, the methane concentration of air entering the stratosphere is held at $1.75 \mathrm{ppmv}$. Although the model is run for both hemispheres, annual mean boundary conditions and results are essentially symmetric about the equator, so we present only northern hemisphere results in the following figures.

\section{Results from the simple model}

Figures 6-13 show results for several experiments with the simple model. The "Modern" runs have an annual mean $\Delta T_{p e}$ of $46 \mathrm{~K}$, with the temperature at the equator being $302 \mathrm{~K}$, and the poles varying from $236 \mathrm{~K}$ to $276 \mathrm{~K}$ over the seasonal cycle. The "Eocene" runs have an annual mean $\Delta T_{p e}$ of $15 \mathrm{~K}$, with the temperature at the equator again $302 \mathrm{~K}$, and the polar temperatures varying from $273 \mathrm{~K}$ to $293 \mathrm{~K}$ over the seasonal cycle. In the base runs, PSC particle number densities were set to $10 \mathrm{~cm}^{-3}$. Additional runs were performed with particle number densities of $0.01,0.1$, and $1 \mathrm{~cm}^{-3}$. Runs were performed with widely varying
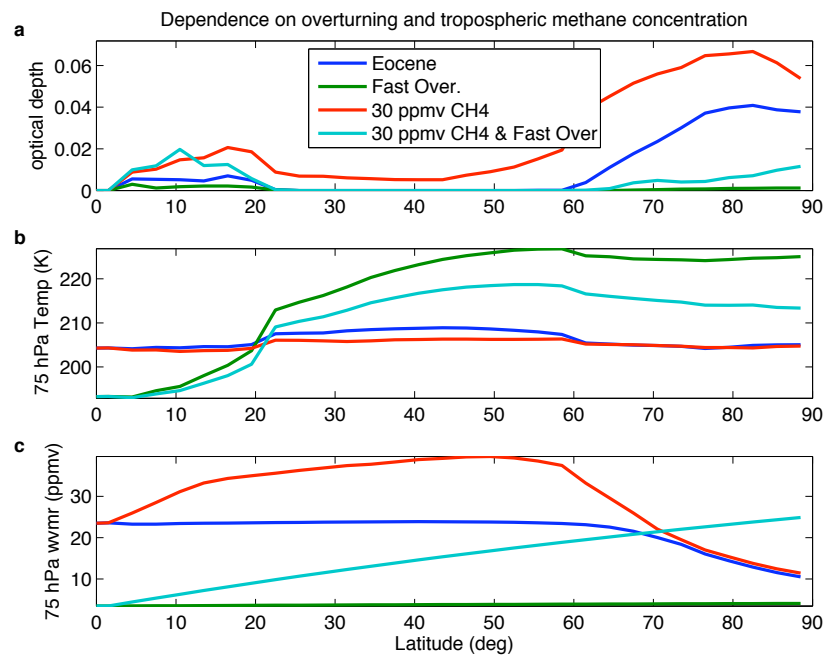

Fig. 6. Two-dimensional model results for total PSC optical depth (a), $75 \mathrm{hPa}$ temperature (b) and $75 \mathrm{hPa}$ water vapor volume mixing ratio (c) for model experiments with varying tropospheric methane concentrations and varying overturning circulation strength. In all cases the surface temperature and static stability distributions are set to Eocene values (low meridional temperature gradient, low surface static stability gradient)

methane concentrations, and with varying stratospheric overturning circulations strengths. Runs were also performed with "Eocene" overturning and "Modern" surface temperatures, and with "Modern" overturning for "Eocene" surface temperatures. Annual mean PSC optical depths reflect a seasonal cycle during which PSCs are typical absent except in winter, so that the annual mean optical depth is about four times smaller than winter-time mean values. For the "Eocene" control case, maximum PSC optical depths were 0.22 , corresponding to a cloud water mixing ratio of 0.4 ppmm.

Figure 6 shows results for "Eocene" conditions with varying overturning circulation strength and for varying levels of tropospheric methane. The top panel shows annual mean infrared optical depth of simulated PSCs as a function of latitude. Optically thick PSCs are only present when the overturning circulation is reduced along with the pole-to-equator temperature gradient, because otherwise, with fast ("Modern") overturning, temperature at the pole are too warm to allow condensation, even with water vapor mixing ratios of $15 \mathrm{ppmv}$ (bottom panel). Fast overturning also results in colder temperature at the tropical tropopause $(190 \mathrm{~K}$, versus $203 \mathrm{~K}$ for "Eocene" overturning). This in turn results in much lower water vapor concentrations, if tropospheric methane is held fixed. The bottom panel shows that sedimentation from PSCs reduces water vapor concentrations towards the poles when PSCs are present.

Figure 7 shows results for varying overturning circulation and tropospheric methane mixing ratio for "Modern" conditions. For this model, tropospheric temperature conditions 

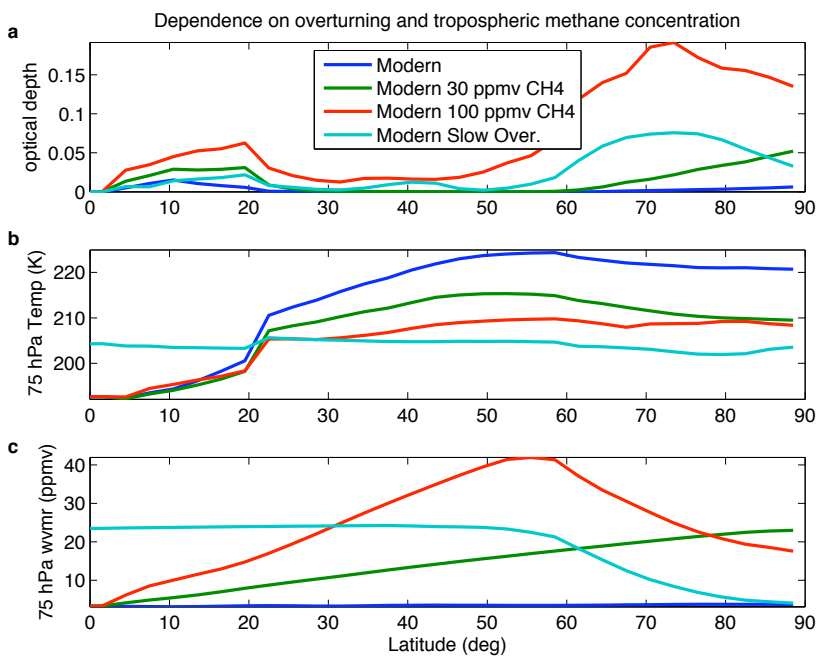

Fig. 7. As for Fig. 6, for the Modern case, for two cases with Modern surface temperature but elevated methane concentrations, and for the Modern case with slow (Eocene-level) overturning.
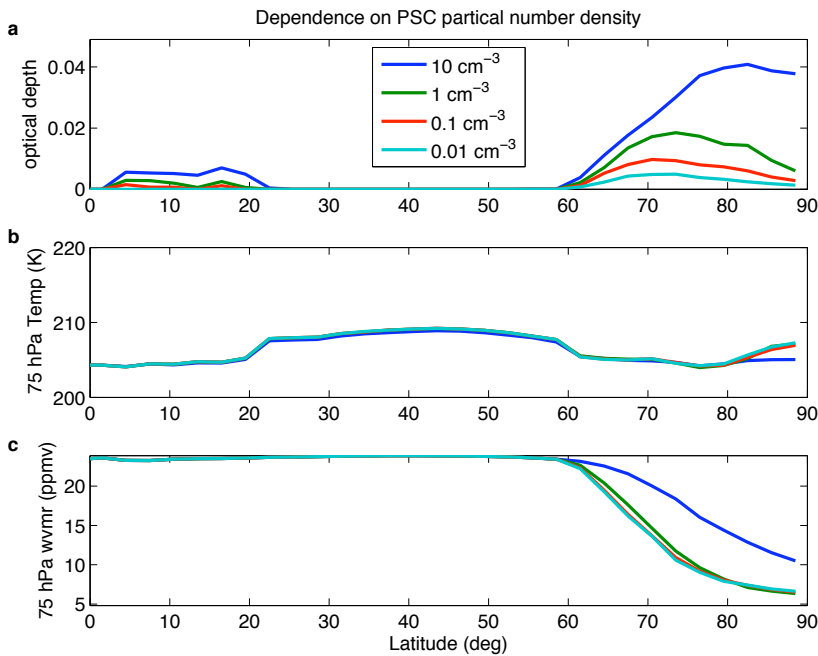

Fig. 8. As for Fig. 6, for four different values of the PSC particle number density.

do not have much direct (radiative) impact on stratospheric temperatures, so the results are very similar to the results for "Eocene" conditions. Optically deep PSCs arise when sufficient stratospheric water vapor is present (due to either reduced stratospheric overturning, warming the tropical tropopause, or increased tropospheric methane, or both), and temperatures in the polar regions are cold enough (for a given amount of water vapor) to form this clouds. For "Modern" stratospheric overturning values, this requires extremely high methane concentrations - over 100 times present values.

Figure 8 shows results for "Eocene" conditions with a range of assumed particle number densities. Optical depths are much higher for higher number densities, for three reasons. First, sedimentation of cloud particles is smaller for higher number densities, since particles are smaller and have
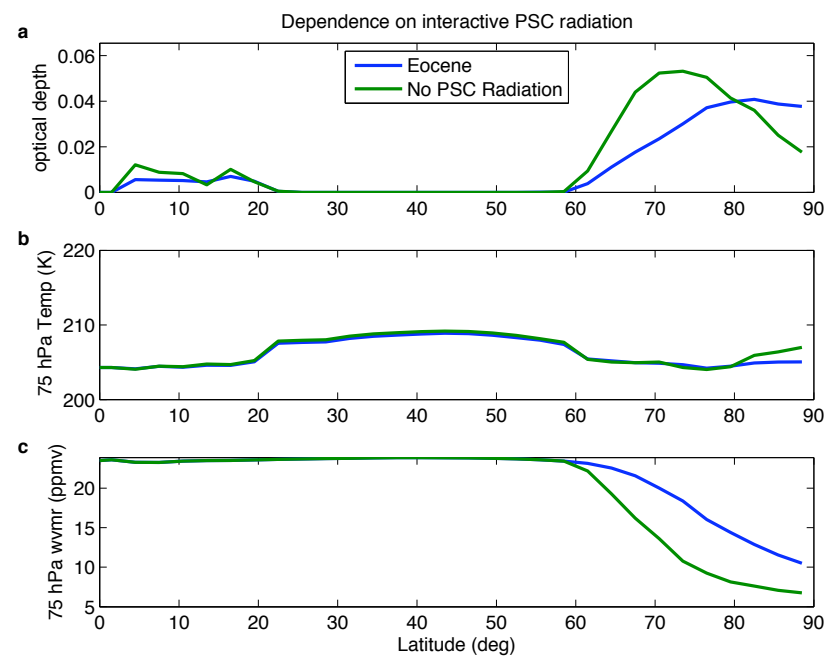

Fig. 9. As for Fig. 6, for the control Eocene case, and for a case with PSC radiative effects turned off.

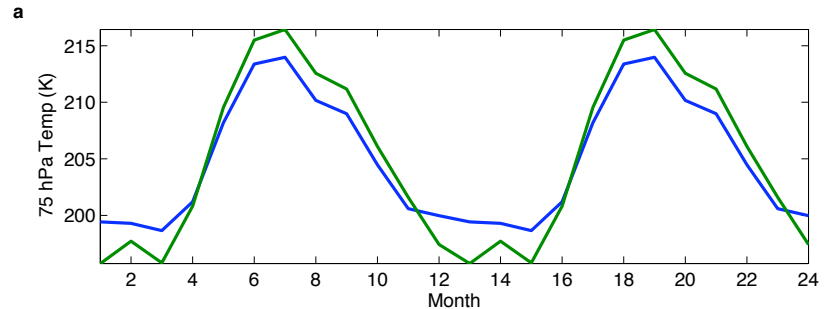

b

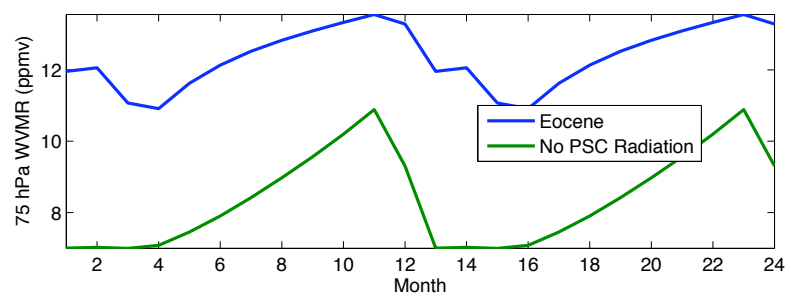

Fig. 10. Seasonal cycle of (a) $75 \mathrm{hPa}$ temperature and (b) $75 \mathrm{hPa}$ water vapor for the control Eocene case, and for a case with PSC radiative effects turned off.

slower terminal velocities. Second, optical depth is increased because the surface area to volume ratio of small particles is larger than that of large particles. Finally, PSC radiative effects cause warming which results in reevaporation of PSC in situ before sedimentation can occur. Note that for all number densities at or below $1 \mathrm{~cm}^{-3}$, water vapor concentrations are substantially lower than for a high number density $\left(10 \mathrm{~cm}^{-3}\right)$. This is so both because of the higher water losses by sedimentation with lower number density and because wintertime temperatures for clouds with high PSC number densities and high optical depths are substantially higher, so less water vapor is lost by condensation and sedimentation. These factors are disentangled in Figs. 9 and 10, which explore the impact of PSC radiative forcing on the model results. 
a
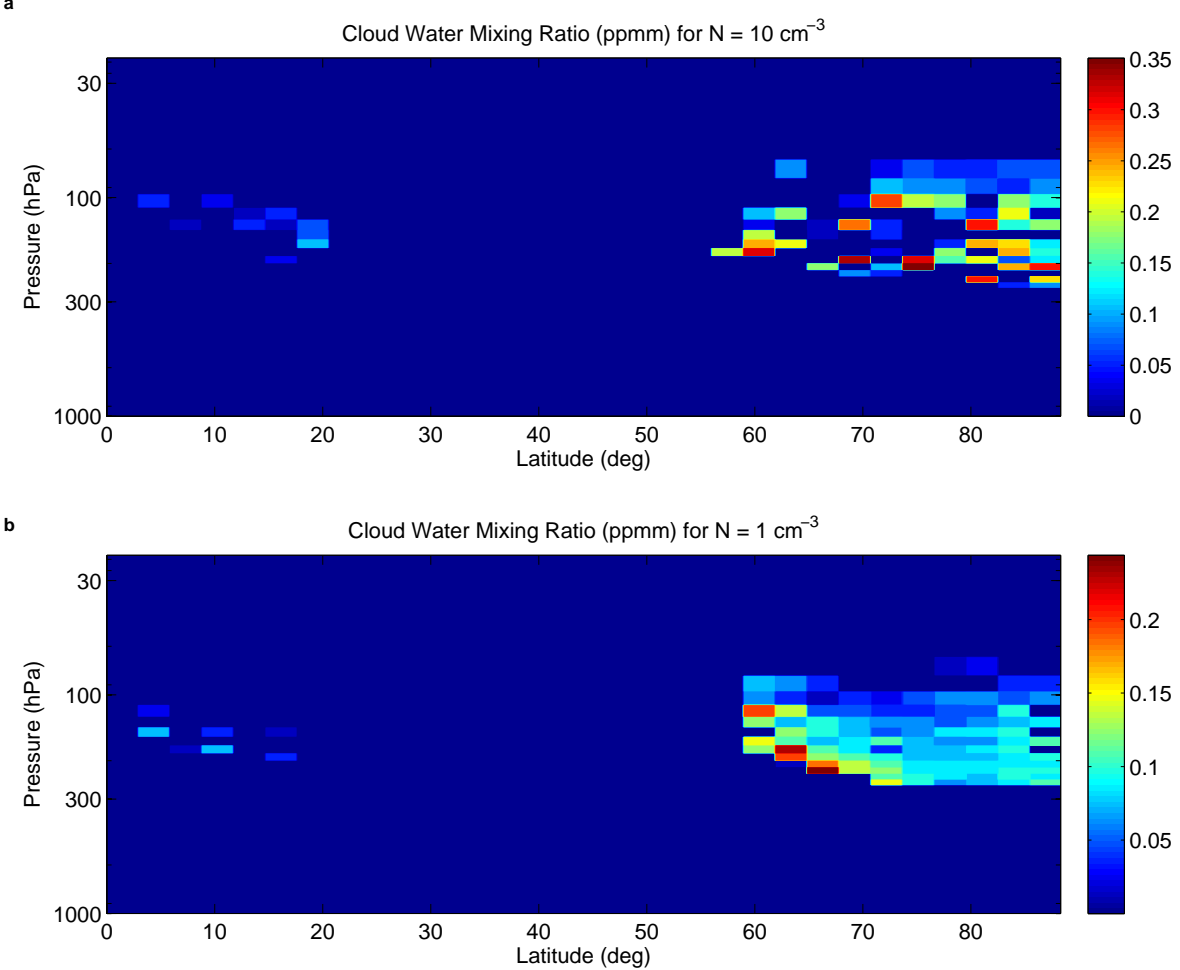

Fig. 11. Dependence of PSC uniformity on particle number density. Panel (a) shows Eocene March cloud water mixing ratio for PSC particle number density equal to 10 per cubic centimeter. Panel (b) shows January cloud water mixing ratio for PSC particle number density equal to 1.0 per cubic centimeter.

Figure 9 shows that when PSC radiative effects are turned off, PSCs are shifted to lower latitudes, and water vapor concentrations are substantially reduced. Figure 10 shows the time series of monthly mean $75 \mathrm{hPa}$ temperature and water vapor mixing ratio for the Eocene control case, and the case with PSC radiation turned off. When PSC radiative effects are operating, temperatures do not fall as low in winter, because the PSC raise the radiative equilibrium temperature of the stratosphere by increasing the emissivity in regions where there is strong upwelling infrared radiation. The warmer temperatures mean that water vapor mixing ratio is not reduced so much via condensation and sedimentation. The higher water vapor concentrations result in cooler temperatures for much of the year, when the energy balance in the stratosphere is between heating by ozone absorption of solar radiation, and infrared cooling, partially via water vapor. Thus the annual mean temperatures shown in Fig. 8 are only slightly cooler for high number densities.

Figure 11 shows the two dimensional distribution of cloud water mixing ratio for two different number densities. It helps to explain why temperature in Fig. 8b depends so strongly on PSC particle number density. For low number densities (Fig. 11b), the radiative heating effect of PSCs is small, and the pattern of cloud water mixing ratio in latitude and pressure is uniform. At higher number density, the tendency of PSCs to raise local temperatures causes a patchy pattern of cloud water mixing ratio: temperatures hover near the frost point, and when temperatures dip below the frost point, large amount of water can condense on the large number of particles, without much loss by sedimentation. Temperatures in the grid squares with clouds rise, causing evaporation. This cycle of condensation and evaporation leads to a patchy distribution of cloud water for high number densities, as shown in Fig. 11a. Similar results are obtained for $6 \mathrm{hPa}$ vertical resolution, as shown in Supplementary Fig. 1 (http://www.clim-past.net/4/69/2008/ cp-4-69-2008-supplement.pdf): the cloud water mixing ratio is more variable at higher resolution for both number densities, but the tendency to greater vertical homogeneity at lower number density remains clear. We can quantify this relationship by noting that the vertical lag-1 autocorrelation of cloud water mixing ratio in these figures is 0.42 for $N=10 \mathrm{~cm}^{-3}$ and 0.55 for $N=1 \mathrm{~cm}^{-3}$ at $15 \mathrm{hPa}$ resolution, at 0.27 for $N=10 \mathrm{~cm}^{-3}$ and 0.35 for $N=1 \mathrm{~cm}^{-3}$ at $6 \mathrm{hPa}$ resolution.

The modeled patchiness of PSC cloud water mixing ratio does not reduce PSC radiative impacts at the surface: Fig. 12 compares the surface radiative impact for comparable PSC optical depths $(\sim 0.1$, averaged over the winter months) for the case of explicitly calculated PSC optical depth and the case of a fixed uniform PSC optical depth applied through 


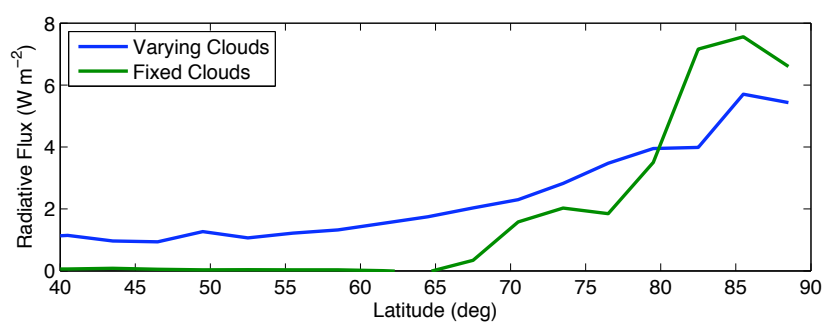

Fig. 12. Dependence of radiative flux at the model surface due to PSCs for the cases of explicitly calculated PSCs and fixed uniform PSCs (as labeled).

the wintertime polar stratosphere. Both cases result in a surface warming of about $4 \mathrm{~W} \mathrm{~m}^{-2}$ averaged over the wintertime polar cap, compared to a case with low number density $\left(0.01 \mathrm{~cm}^{-3}\right)$ and thus negligible PSC optical depth. By contrast, experiments in which PSCs were imposed on one, two, or three days out of every 4 (not shown), show that when PSCs occur only sporadically in time, the radiative forcing for the same average optical depth is reduced by up to half when PSC occur on only one day in four. We emphasize that we do not believe our simple model should be relied upon for quantitative estimation of surface warming, since tropospheric clouds and dynamics are treated so simply.

We have shown that low overturning circulation is necessary in our simple model to allow temperatures low enough to form optically thick PSCs. Figure 13 addresses the question of how the reduced stratospheric water vapor and methane transport associated with reduced overturning affects the water vapor concentrations and PSC optical depth. Both runs shown here are for "Eocene" conditions, but the curves labeled "Fast Transport" have water vapor and methane transport rates corresponding to "Modern" conditions (three times greater than "Eocene" conditions), while the cooling and warming due to vertical motions in the stratosphere are held fixed at "Eocene" levels. As expected, panel c of this figure shows that water vapor concentrations are larger for the "Fast Transport" case, as are PSC optical depths. These effects should be contrasted with the results shown in Figs. 6 and 7 , where both the transport and dynamic heating and cooling associated with the overturning circulation are changed- in that case stronger stratospheric overturning is clearly associated with much reduced PSC optical depth, due to increased high latitude temperatures. Thus, overturning changes do affect PSC optical depth via changes in water vapor supply to the polar regions, but this effect is dwarfed by the effect of overturning changes on tropopause temperature (and thus stratospheric water vapor concentration) and on polar night temperatures. For both of these latter mechanisms, increased overturning strongly reduces PSC optical depth.
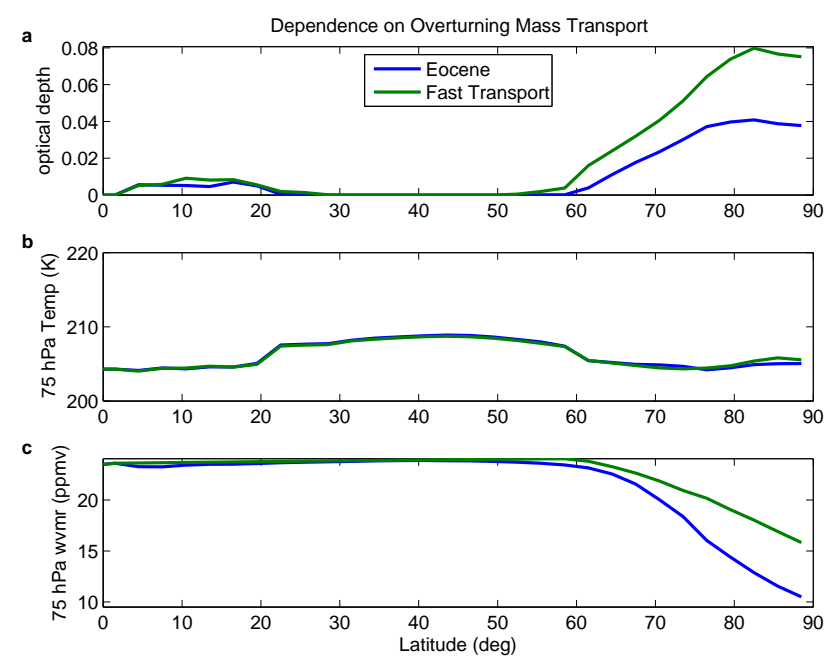

Fig. 13. As for Fig. 6, for the Eocene case, and for a the case of Modern transport.

\section{Discussion and conclusions}

Our simple modeling results demonstrate that PSCs of optical depth sufficient to cause significant surface warming require high particle number densities (exceeding $1 \mathrm{~cm}^{-3}$ ), and either weak stratospheric overturning or extremely high tropospheric methane concentrations.

As speculated in KSA, we demonstrate here that in our simple model optically thick PSC's self-heating can substantially reduce water loss via sedimentation. Optically thick PSC warm the stratosphere locally, so that model temperature tend to hover around the frost point. Thus optically thick PSCs can evaporate before substantial sedimentation takes place. This provides some basis for arguing that in a moister stratosphere the fractional rate of loss via sedimentation might not be substantially larger than in the present, helping explain sustained wintertime high latitude warmth.

We have shown that in the absence of reduced overturning circulation (which tends to cool the polar stratosphere), very high levels of water vapor (whether from methane oxidation or some other source) are required to allow optically thick PSCs, even for very high number densities.

Our results further demonstrate that the reduction of water vapor transport associated with weak overturning does not prevent formation of optically thick PSCs, for sufficiently high particle number density. PSC particle number densities of $10 \mathrm{~cm}^{-3}$ have been observed, but are uncommon in the present atmosphere, where much lower densities are typical (Peter, 1997). Thus, for optically thick PSCs to have been part of the solution to Eocene polar warmth, there must have been some change in ice-formation microphysics. One can speculate that in a much moister stratosphere, more favorable condensation nuclei would be rapidly removed, leaving only the background sulfate aerosol, with a number density 
of approximately $6 \mathrm{~cm}^{-3}$ (McLinden et al., 1999; Fortin et al., 2003).

Our understanding of the factors controlling PSC particle number density is so poor that we have little basis for preferring its treatment in either the simple model or in WACCM, but our results from the simple model indicate a very strong sensitivity of the radiative impact of PSCs to particle number density. This provides a strong motivation for improved understanding of the physical mechanisms controlling ice particle nucleation and growth in the stratosphere.

Acknowledgements. This work was supported by grant ATM0457515 from the National Science Foundation. JFL was supported by the SciDAC project from the Department of Energy. This research used resources of the National Energy Research Scientific Computing Center, which is supported by the Office of Science of the US Department of Energy under Contract No. DE-AC03-76SF00098. The National Center for Atmospheric Research is operated by the University Corporation for Atmospheric Research under sponsorship of the National Science Foundation. The manuscript benefited greatly from the careful reading and suggestions of two anonymous reviewers.

Edited by: M. Claussen

\section{References}

Brock, C. A., Hamill, P., Wilson, J. C., Jonsson, H. H., and Chan, K. R.: Particle Formation in the Upper Tropical Troposphere: A Source of Nuclei for the Stratospheric Aerosol, Science, 270, 1650-1653, 1995.

Carslaw, K. S., Peter, T., and Clegg, S. L.: Modeling the composition of liquid stratospheric aerosols, Rev. Geophys., 35, 125-154, 1997.

Chou, M. D., Suarez, M. J., Liang, X. Z., and Yan, M. M. H.: A Thermal Infrared Parameterization for Atmospheric Studies, NASA Technical Memorandum TM104606,19, 2001

Chou, M. D. and Suarez, M. J.: A solar radiation parameterization for atmospheric studies, NASA Technical Memorandum TM104606, 11, 1999

Daerden, F., Larsen, N., Chabrillat, S., Errera, Q., Bonjean, S., Fonteyn, D., Hoppel, K., and Fromm, M.: A 3D-CTM with detailed online PSC-microphysics: analysis of the Antarctic winter 2003 by comparison with satellite observations, Atmos. Chem. Phys., 7, 1755-1772, 2007, http://www.atmos-chem-phys.net/7/1755/2007/.

Deshler, T., Hervig, M. E., Hofmann, D. J., Rosen, J. M., and Liley, J. B.: Thirty years of in situ stratospheric aerosol size distribution measurements from Laramie, Wyoming $\left(41^{\circ} \mathrm{N}\right)$ using balloon-borne instruments, J. Geophys. Res., 108, 4167, doi:10.1029/2002JD002514, 2003.

Drdla, K., Schoeberl, M. R., and Browell, E. V.: Microphysical modeling of the 1999-2000 Arctic winter: 1. Polar stratospheric clouds, denitrification, and dehydration, J. Geophys. Res., 107, 8312-8332, 2002.

Fortin, T. J., Drdla, K., Iraci, L. T., and Tolbert, M. A.: Ice condensation on sulfuric acid tetrahydrate: Implications for polar stratospheric clouds, Atmos. Chem. Phys., 3, 987-997, 2003, http://www.atmos-chem-phys.net/3/987/2003/.
Heymsfield, A. J. and Iaquinta, J.: Cirrus Crystal Terminal Velocities, J. Atmos. Sci., 57, 916-938, 2000.

Holton, J. R., Haynes, P. H., McIntyre, M. E., Douglass, A. R., Rood, R. B., and Pfister, L.: Stratosphere-troposphere exchance, Rev. Geophys., 33, 4, 403-439, 1995.

Hu, R.-M., Carslaw, K. S., Hostetler, C., Poole, L. R., Luo, B., Peter, T., Füeglistaler, S., McGee, T. J., and Burris, J. F.: Microphysical properties of wave polar stratospheric clouds retrieved from lidar measurements during SOLVE/THESEO 2000, J. Geophys. Res., 107(D20), 8294, doi:10.1029/2001JD001125, 2002.

Huber, M. and Sloan, L. C.: Heat transport, deep waters, and thermal gradients: Coupled simulation of an Eocene Greenhouse Climate, J. Geophys. Res., 28, 3481-3484, 2001.

Kawamoto, N. and Shiotani, M.: Interannual variability of the vertical descent rate in the Antarctic polar vortex, J. Geophys. Res., 105, 11935-11 946, 2000.

Kirk-Davidoff, D. B and Lindzen, R. S.: An Energy Balance Model Based on Potential Vorticity Homogenization, J. Climate, 431448, 2000.

Kirk-Davidoff, D. B., Schrag, D. P., and Anderson, J. G.: On the Feedback of Stratospheric Clouds on Polar Climate, Geophys. Res. Let., 29(11), 1556-1559, doi:10.1029/2002GL014659, 2002.

Korty, R. L. and Emanuel, K. A.: The dynamic response of the winter stratosphere to an equable climate surface temperature gradient, J. Climate, 20, 5213-5228, doi:10.1175/2007JCLI1556.1, 2007.

Lamarque, J.-F., Kiehl, J., Shields, C., Boville, B. A., and Kinnison, D. E.: Modeling the response to changes in tropospheric methane concentration: Application to the Permian-Triassic boundary, Paleoceanography, 21, PA3006, doi:10.1029/2006PA001276, 2006.

McLinden, C. A., McConnell, J. C., McElroy, C. T., and Griffioen, E.: Observations of Stratospheric Aerosol Using CPFM Polarized Limb Radiances, J. Atmos. Phys., 56, 233-240, 1999.

Peter, T.: Microphysics and Heterogeneous Chemistry of Polar Stratospheric Clouds, Annu. Rev. Phys. Chem., 48, 785-822, 1997.

Scheele, M. P., Siegmund, P. C., and van Velthoven, P. F. J.: Stratospheric age of air computed with trajectories based on various 3D-Var and 4D-Var data sets, Atmos. Chem. Phys., 5, 1-7, 2005, http://www.atmos-chem-phys.net/5/1/2005/.

Schneider, T.: The tropopause and the thermal stratification in the extratropics of a dry atmosphere, J. Atmos. Sci., 61, 1317-1340.

Sloan, L. C. and Pollard, D.: Polar stratospheric clouds: a highlatitude warming mechanism in an ancient greenhouse world, Geophys. Res. Lett., 25, 3517-3520, 1998.

Tabazadeh, A., Toon, O. B., and Jensen, E. J.: Formation and implications of ice particle nucleation in the stratosphere, Geophys. Res. Lett., 24(16), 2007-2010, 1997.

Thomas, A., Borrmann, S., Kiemle, C., et al.: In situ measurements of background aerosol and subvisible cirrus in the tropical tropopause region, J. Geophys. Res., 107, 4763, doi:10.1029/2001JD001385, 2002.

Thomason, L. and Peter, T. (Eds.): Assessment of Stratospheric Aerosol Properties, SPARC Report No. 4, WMO, 2006.

Toon, O. B., Ferry, G., Turco, R. P., Jordan, J., and Goodman, J.: Physical proccessses in polar stratospheric ice clouds, J. Geophys. Res., 94(D9), 11 359-11380, 1989. 